\title{
LOS CONQUISTADORES ESPAÑOLES DERROTADOS. UNA MIRADA DESDE EL CINE Y LOS VIDEOJUEGOS
}

Silvina MONDRAGÓN

CESAL-UNICEN

Javier CHIMONDEGUY

CONICET-CESAL

\section{RESUMEN}

El artículo busca revisitar la figura de conquistadores derrotados, que están lejos de lo que la historiografía tradicional intentó asociar al concepto de conquistador heroico e invencible. Se relaciona esta característica de vencidos con el contexto social de sus expediciones, la sociedad de la que forman parte y su lugar en la misma. El artículo presenta una comparación entre las fuentes del período, la producción de los historiadores y las resignificaciones del cine y los videojuegos

Palabras clave: Conquistadores - Historia - Cine - Videojuegos

\section{ABSTRACT}

The article seeks to revisit the story of defeated conquerors, which are far away from what traditional historiography has always remarked as the heroic and undefeatable conqueror of Indias. It is also related with the social context of the expeditions, the society they were part of and their own place in it. The article also provides a comparative study between the sources from the historical period, the historians' production and the resignification of cinema and videogames.

Key words: Conquerors - History - Cinema - Videogames

\section{ENTRE LA FICCIÓN Y LA REALIDAD: AGUIRRE Y ORELLANA}

Tanto el cine como los videojuegos se han ocupado de dos cuestiones que la Historia científica, ha infravalorado, por omisión o descuido. 
En primer lugar, las condiciones de la vida de los primeros europeos que llegaron a América con permiso de exploración de la Corona, los llamados "conquistadores", no han sido estudiadas. La clave que proponemos, sus cuitas personales así como su vida cotidiana, no ha merecido la atención de los historiadores profesionales, que en su mayoría, bajo el estigma del eurocentrismo, los han reducido a la condición de agentes de la corona en América. Algunas excepciones son los estudios de Todorov y Lafaye, quienes intentan rescatar el registro humano en sus trabajos en torno a la conquista desde perspectivas ligadas a la lingüística y a la antropología (Todorov, 1987; Lafaye, 1999).

No obstante, tanto en los videojuegos que recrean a estos personajes como en los films de corte histórico, es observable que la recreación de época ha sido hecha por historiadores profesionales y, en muchos casos, es evidente también la utilización de fuentes históricas ${ }^{1}$.

En segundo lugar, los conquistadores que no lograron garantizar el éxito de sus empresas colonizadoras tampoco han recibido la atención de los historiadores. Los "conquistadores derrotados" por ósmosis han sido identificados con el fracaso de los agentes de un imperio colonial, que para el siglo XVI lideraba el palimpsesto de potencias europeas. Es obvio que la imagen de un imperio poderoso y de un emperador magnánimo no era identificable con la de un héroe menguado. Este héroe debilitado coincidía en los principios de la modernidad con un sujeto humano que se encontraba débil, aislado, dubitativo y solo, solamente atormentado por aquel anhelo de convertirse en un héroe atemporal como Eneas, Aquiles o el $\mathrm{Cid}^{2}$.

Sin embargo, aunque estos conquistadores vencidos no ostentan un lugar protagónico en el registro historiográfico; sí aparecen retratados con sus circunstancias tanto en los videojuegos como en el cine.

Nos centraremos principalmente en relatos que ejemplifican lo dicho a partir de dos registros audiovisuales, centrados en la primera fundación de la ciudad de Buenos Aires por un lado y en la misión que tenía por objeto la búsqueda de El Dorado en el norte de Ecuador, a principios del siglo XVI.

La película Misteriosa Buenos Aires, dirigida por Alberto Fischerman, Óscar Barney Finn y Ricardo Wullicher en 1981, está basada en un libro de cuentos del escritor argentino Manuel Mujica Laínez. El autor recurre a los cuentos para reconstruir la historia de la ciudad, mezclando personajes ficticios con tramas históricas concretas. Su recuento abarca un amplio marco temporal que va desde la primera fundación de la ciudad en 1536 (fallida), hasta los festejos del centenario de la Revolución de Mayo en 1910, ya que constituye un evento de gran envergadura para el fortalecimiento del incipiente estado nacional.

El largometraje toma solamente tres de estos cortos relatos, cada uno dirigido por un director en particular. El primero de ellos, El Hambre (dirigido por Fischerman), relata la

1 Un ejemplo paradigmático es el film Aguirre: la ira de Dios, dirigida por el binomio der Zorn Gottes y Werner Herzog en 1972. La película está estructurada a partir del relato de fray Ginés de Carbajal que narró las vicisitudes de Lope de Aguirre y sus expedicionarios desde que partieron de los andes peruanos, hasta que atravesaron el río Amazonas en busca de la mítica ciudad de El Dorado.

2 La mirada historiográfica más tradicional, se ha ocupado de resaltar los valores heroicos y cristianos en detrimento de un abordaje "humano" de estos personajes: "Un hombre desnudo de ambición, carente de valor personal, poco sufrido en su cuerpo, no hubiera podido andar tantas leguas, padecer tanta hambre y sed, ser herido una y otra vez y ver desvanecidas sus esperanzas en muchísimas ocasiones, sin sucumbir a este régimen de circunstancias difíciles. Ambición, valor, resignación: he aquí los tres rasgos indiscutibles del conquistador" (López Pego, 1955: 321).

Quaderns, 13 (2018), pp. 85-92 
primera fundación de Buenos Aires por Pedro de Mendoza a partir de las andanzas de dos hermanos que componían la expedición. Devastados por el hambre, los hombres deciden comerse los cadáveres de unos soldados ahorcados por orden del comandante, que al igual que ellos, habían cometido un grave delito para la lógica de la conquista: matar un caballo para saciar el hambre.

No por azar el corto se sostiene sobre un fondo absolutamente sombrío en el que sobresalen el estado constante de suciedad de las ropas, la delgadez de los cuerpos y sobre todo, la agudización del instinto de supervivencia de los personajes amenazados por la inanición.

Como la antropofagia estaba condenada por la Iglesia, los hermanos deben implementar un plan para poder comer: mientras uno de ellos estaba de guardia, el otro robaría los cuerpos. Sin embargo, uno de los hermanos se queda dormido mientras comparte la escena con uno de los nobles, que sobresale por estar ataviado con un tapado de nutria, lo que sirve al director para remarcar la identificación entre rango estamental y probabilidades de supervivencia.

Cuando el joven despierta, ataca al sujeto a quien es evidente que despreciaba por su condición nobiliar y todos los privilegios que de ella se desprenden. Cuando le arranca la mano para devorarla, el film llega a un clímax en el que lo grotesco de la conquista queda al descubierto.

Sin embargo, y para remarcar la agudización de la miseria vital del atacante, al devorar la mano siente que muerde un anillo, y descubre que es el anillo de su hermano. A quien asesinó no es al noble del tapado de nutria, sino a su hermano, quien previamente había asesinado al hombre del tapado de nutria. Desolado, escapa de la ciudad y se entrega a los indios, para que lo juzguen.

Por último, el relato abarca temas ancestrales como el fraticidio, los bajos instintos, o lo más irracional de la condición humana, a través de un prisma atemporal que busca retratar la humanidad tanto de los conquistadores como de los integrantes de las avanzadas europeas en suelo americano.

En la película alemana de la década de 1970, Aguirre, la Ira de Dios dirigida por Werner Herzog, encontramos nuevamente la historia de un conquistador que fracasa en sus exploraciones en suelo americano. El explorador en cuestión es Pedro de Ursua y el segundo al mando de la expedición es quien da nombre al título del film: Lope de Aguirre.

En este caso se trata de un relato puramente histórico. La fuente sobre la que se basa es la crónica que el dominico Gaspar de Carvajal escribió y publicó en 1541 cuando acompañó en su expedición a Francisco de Orellana por el río Amazonas, que acababa de encontrar ${ }^{3}$. En esta crónica, Relación del nuevo descubrimiento del famoso río Grande que descubrió por muy gran ventura el capitán Francisco de Orellana (De Carvajal, 1541), el fraile narra cómo la expedición que buscaba el País de la Canela y El Dorado termina su travesía en frustración, desilusión y desencanto. Pero no todo había sido en vano: los españoles se encontraron con el río más grande del mundo (Benites, 2011).

3 Se trata de un personaje que ha conseguido la atención de los investigadores. De hecho, existen varios trabajos que indagan sus andanzas por América del Sur. Los XL Coloquios Históricos de Extremadura, fueron dedicados a Francisco de Orellana en el quinto centenario de su nacimiento, Trujillo del 19 al 25 de septiembre de 2011. 
Al igual que en la estética de El Hambre, las escenas son muy oscuras y explícitas y los tiempos de la película son lentos y tediosos, incluso en comparación con las cintas contemporáneas, porque las largas escenas bajo la lluvia de la selva sudamericana y los sufridos diálogos dan cuenta y hacen vívida para el espectador la penosa vivencia de Lope de Aguirre en su ambiciosa expedición en pos de encontrar la ciudad de El Dorado.

Desde el comienzo de la misma, el director privilegia los planos de la lenta navegación de los españoles a lo largo del Río Marañon (Perú) en tres balsas.

La cinta hace referencia de manera soslayada y de forma constante, a un juego de opuestos: lo europeo y lo americano. Tan fuerte es esta asociación de lo amazónico y americano con lo salvaje y bárbaro, que la cinta inspiró a la película de Francis Ford Coppola de 1979, Apocalypse Now, que narra los sinsabores de un líder militar estadounidense en la Guerra de Vietnam. Interpretamos que esto prueba una mirada eurocéntrica atemporal respecto de sociedades no occidentales.

El imaginario que asocia lo europeo a lo civilizado está de hecho presente. Incluso la elección de actores alemanes refuerza esta diferenciación entre lo europeo y lo local: lo indígena es por definición primitivo y arcaico.

Los reflejos en la película de la crónica de Carvajal son notorios tanto por los paisajes, como por la lenta navegación a través del río y el peligro constante que acecha a los europeos.

Encontramos nuevamente a un fatigado Francisco de Orellana, en el juego de estrategia Age of Empires II: The Forgotten del año 2013. Lo más llamativo de este videojuego es que su aparición se debe a una demanda de los seguidores del juego, que terminaron por crear una expansión del original, finalmente reconocida por la empresa que había creado el juego.

El enfoque sobre el conquistador del videojuego es asimilable a la que se puede encontrar en el film Aguirre, la Ira de Dios. Se puede considerar una influencia notable del film sobre el videojuego; aunque en el juego la trama se encuentra centrada tanto en Francisco de Orellana como en Gonzalo Pizarro.

Como señalamos, Francisco de Orellana era un conquistador español reconocido por haber sido el primer europeo en encontrarse con el río Amazonas. Emparentado con los Pizarro, en el videojuego aparece como un sobrino de ellos, aunque para los historiadores esto no está probado, por lo que en su mayoría consideran que se trataba de un primo.

Asimismo, al ser jugado en primera persona, el jugador puede elegir los caminos a seguir, como señala Juan Francisco Jiménez Alcázar al analizar al medievalist gamer, aunque al estar el juego pensado para el fracaso de la misión, o que finalmente el Dorado no sea encontrado, por más intentos que haga el jugador, siempre terminará en fracaso la expedición. Algo similar en términos teleológicos sucede con la campaña del Emperador Moctezuma, del juego Age of Empires: Conquerors, dada la "conquista" formal de los europeos del universo conocido por los indígenas.

Sin embargo, la mirada que ofrece el juego sobre el mundo aborigen no es identificable con la de la película de los años setenta del siglo XX. Aquí encontramos un hecho asimilable al que señala Juan Francisco Jiménez Alcázar cuando compara el mundo islámico con las cruzadas: "Para el mundo islámico se posee otro tipo de parámetros, pues en esa perspectiva "desde el otro lado» convierte al fenómeno en una actualización diversa: el "cruzado» es un agresor, por definición, y lo podemos ver hoy en los recientes sucesos donde el grito de protesta de determinado sector musulmán se vincula al insulto o provocación por parte 
de los «nuevos cruzados»". En este caso, el conquistador y el europeo aparecen como predadores por definición y lo cristiano como un sinsentido oscurantista.

En este sentido, no es esperable encontrar en el juego un registro histórico fidedigno, ya que el objetivo es sumergir al jugador en un escenario virtual y visual, que busca reconstruir los paisajes socialmente asociados a la "conquista" y a la "modernidad": el descubrimiento del Nuevo Mundo, el sincretismo religioso entre catolicismo y prácticas indígenas o el encuentro entre individuos portadores de diferentes constructos culturales

En la avanzada que hace la compañía de los exploradores, lo indígena aparece asociado a la presencia de la Iglesia en suelo americano. A medida que el jugador avanza, se encuentra con templos custodiados por sacerdotes y por guerreros, indistintamente. Aunque Orellana (que debe llegar a salvo a Quito para encontrarse con su tío Gonzalo Pizarro), avanza con relativa facilidad, el personaje no deja de depender de la habilidad del jugador para concretar el avance.

La reconstrucción de la ciudad de Quito en el siglo XVI es impactante. Las imágenes logran materializar la cuestión del sincretismo y de la cristianización forzosa, al resaltar las figuras de los clérigos y la gran catedral de la ciudad.

En las cercanías del espacio donde está emplazada la catedral encontramos un malestar social generalizado.

Esto puede verse relacionado con el pasaje de las Crónicas de Carvajal, donde el mismo señala que: "se determinó de pasar adelante y lo seguir, aunque los vecinos de la tierra se lo estorbaban por haber de pasar por tierra muy belicosa y fragosa, y que temían lo matasen como habían hecho a otros que habían ido con muy gran acopio de gente. Pero, no obstante esto, por servir a su majestad determinó con todo este riesgo de seguir tras el dicho gobernador; y así, padeciendo muchos trabajos así de hambres como de guerras que los indios le daban, que por no llevar más de 23 hombres muchas veces le ponían en tanto aprieto que pensaron ser perdidos y muertos en manos de ellos» (De Carvajal, 1541).

Después de avanzar Gonzalo y Francisco de Orellana juntos, se deben separar en el videojuego, relato que también encontramos casi textual en las Crónicas de Carvajal.

Según el fraile, tuvieron que andar alrededor de mil leguas desde el lugar en que dejaron a Pizarro. Tanto el videojuego como la crónica coinciden en que Pizarro se separó de Orellan a causa de la escasez de alimentos.

Una de las misiones del videojuego consiste en pelear contra las Amazonas, que dieron el nombre al río, y fueron llamadas de esta manera por el propio Carvajal. Los personajes que enfrentan son las Arqueras Amazonas y las Guerreras Amazonas.

En la siguiente misión, Orellana se enfrenta a los Caníbales. Es aquí donde finaliza la partida. No hay en la Crónica original de Carvajal una mención específica a estos grupos caníbales, aunque sí se menciona la hostilidad sufrida, al decir que «Y así se embarcaron porque ya los indios empezaban a pelear y más que, por el agua, venía mucha flota de canoas; y así hicimos a largo del río y dejamos la tierra» (De Carvajal, 1541).

En la crónica del dominico, al avanzar hacia el norte se encuentran con "indios buenos y mansos" hasta que finalmente su travesía termina en la ciudad de Nueva Cádiz, en la isla de Cubagua.

Por motivos comerciales y de la lógica que debe tener el videojuego, este no es el final que encontramos en The Forgotten, El Dorado para la expedición de Francisco de Orellana. 
La "victoria" del juego consiste en que el jugador sea capaz, amenazas bélicas mediante, de construir quince galeones para poder iniciar su periplo hacia el océano; es decir, ganará la partida si logra escapar para volver a Europa.

\section{EL CONTEXTO HISTÓRICO}

Desde el siglo XV y hasta el siglo XVII, Europa creó las condiciones decisivas para la estructuración de la sociedad moderna y el fundamento de su dinámica. El fenómeno más visible de este proceso fue la expansión hacia la periferia ultramarina iniciada por España y Portugal, que tuvo por corolario la articulación de dos imponentes imperios coloniales (Mackenney, 1996; Pagden, 1997; Bennassar, 1980; 1992; Tenenti, 1985; Chaunu, 1975). Metales americanos, pimienta de oriente y esclavos de África se transformaron en el trípode que convirtió el mercado europeo en un mercado mundial (Tenenti, 1985). Sin embargo, los dos imperios asumieron formas diferentes: mientras que Portugal extendió una larga línea de puntos en la costa (puertos, depósitos, factorías) destinada a controlar el tráfico marítimo; la corona española conquistó territorios, sometió las poblaciones locales y vertebró una compleja red de burocracia imperial para administrar las tierras recientemente anexadas al Imperio.

España y Portugal compartían la misma concepción de la economía: la riqueza no se creaba sino que se acumulaba, la lógica medieval de la que habla Pierre Vilar en "El tiempo del Quijote" (Vilar, 1985). Era una concepción estática de la riqueza que la entendía como un bien fijo e inmóvil. Por lo tanto, era necesario monopolizar los mercados como garantías de mayor acumulación. Todo ese proceso de expansión dio origen a lo que Immanuel Wallerstein llamó la "economía mundo europea". Se trataba de un sistema social novedoso, caracterizado por ser una entidad económica, pero no política. Era un sistema mundial, no porque incluyera la totalidad del mundo, sino porque era mayor a cualquier unidad política jurídicamente definida. Y era una economía mundo debido al vínculo básico entre las partes del sistema: la división internacional del trabajo (Wallerstein, 1999).

Pero si en lugar de enfocar el análisis en las grandes estructuras, observamos con escala microscópica las dinámicas sociales de las cuales provenían los expedicionarios, entonces podemos encontrar aproximaciones más cercanas a la conducta de los primeros años de los españoles en el Nuevo Mundo.

Provenían de sociedades atravesadas por procesos de diferenciación económica social, cuyos emergentes eran grupos emergentes que vivían bajo formaciones monárquicas que desde los siglos tardomedievales se empeñaban en volver a concentrar el poder público que habían dejado diluirse en manos, y a favor, de la alta nobleza en los siglos X y XI.

Así, las nuevas lógicas del poder central se desarrollaron en medio de un complejo proceso de centralización estatal que atravesó buena parte de Europa Occidental desde mediados del siglo XIII. Se estaba tramitando un nuevo tipo de poder central que se convertía en rector y en intermediario de los diferentes sectores sociales. Pero no se puede soslayar el hecho de que progresivamente estratificada, la sociedad bajomedieval expulsaba una gran cantidad de súbditos.

Los procesos de diferenciación social, tanto al interior del estamento de los pecheros como al interior de la nobleza que desde mediados del siglo XIV pueden rastrearse, mostraron las contradicciones que eran capaces de conllevar durante la crisis bajomedieval, cuando se enfrentaron con violencia los distintos grupos de una sociedad cada vez más condicionada por la emergencia de una nueva realidad.

Quaderns, 13 (2018), pp. 85-92 
En ocasiones era la propia subsistencia lo que estaba en juego, pero generalmente de lo que se trataba era de una pugna entre quienes estaban deseosos de subir por la escalera del ascenso social y quienes querían detener este movimiento, convencidos, y beneficiarios, de las antiguas normas de funcionamiento del mundo medieval nobiliar. No dejaba de ser una puja por el poder entre grupos e individuos que procuraban modificar el estatus quo estamental vigente (Monsalvo Antón, 2000).

No es difícil localizar los contornos de los expedicionarios españoles en el Nuevo Mundo, en este cuadro de situación en el viejo continente en la modernidad temprana.

\section{CONCLUSIONES}

El análisis de la forma en que los personajes son caracterizados, tanto en los videojuegos como en el cine, se vuelve un requisito necesario para comprender a cabalidad el mensaje y la intencionalidad en cada una de estas formas de relato audiovisual. Es obvio que estas narrativas son articuladas en base a preguntas que el presente busca responder.

También es obvio, que lejos de constituir un relato del registro histórico, los films o los videojuegos explican más cuestiones económico - sociales y culturales del momento histórico del que son producto, que del propio proceso de conquista del Imperio Español.

Lejos de los logros de Hernán Cortés o de Francisco Pizarro, un sinfín de aventureros europeos llegó a América sin conseguir que sus nombres fueran consignados en los anales reales de la conquista.

Invisibles, las más de las veces o velados adrede en algunas ocasiones, casos como los de los tripulantes de la expedición de Magallanes, abandonados a su suerte en un lugar tan inhóspito como San Julián (Argentina) en 1520, siguen conmoviendo al lector ávido.

\section{BIBLIOGRAFÍA CITADA}

Benites, María Jesús, "El Gran Río de las Amazonas: Relatos del desengaño (siglo XVI)", Revista Espéculo, n 48, Universidad Complutense, Madrid, 2011.

Bennassar, Bartolomé, 1492, un mundo nuevo, Madrid, Nerea, 1992.

- Historia Moderna, Madrid, Akal, 1980.

Chaunu, Pierre: La civilización de la Europa clásica, Barcelona, Juventud, 1975.

De Carvajal, Gaspar (s/d) [1541]: "Relación del Nuevo Descubrimiento de famoso Río Grande que descubrió por muy gran ventura el capitán Francisco de Orellana", Quito: Biblioteca Amazonas, vol. I. Publicación Raúl Reyes y Reyes. Transcripción de Fernández de Oviedo y Toribio Medina, Sevilla, 1895.

Lafaye, Jacques Los conquistadores. Figuras y escrituras, Fondo de Cultura Económica, México, 1999

López Pego, Adela, "Anverso y reverso del conquistador español", Argensola, N²4, Huesca, 1955, p. 321.

Mackenney, Richard, "El poder de los señores" en La Europa del siglo XVI, Madrid, Akal, 1996.

Monsalvo Antón, José Ma, La Baja Edad Media. Política y Cultura, Madrid, Síntesis, 2000. Padgen, Anthony, Señores de todo el mundo. Ideologías del imperio en España, Inglaterra y Francia, Barcelona, Península, 1997.

Tenenti, Alberto, La formación del mundo moderno, Barcelona, Crítica, 1985. 
Todorov, Tzvetan, La conquista de América. El problema del otro, Méjico, Siglo XXI, Méjico, 1987.

Vilar, Pierre, "El tiempo del Quijote", en Cipolla, C. y Elliott, T: La decadencia económica de los imperios, Madrid, Alianza, 1985.

Wallerstein, Immanuel, El moderno sistema mundial, México, Siglo XXI, 1999. 